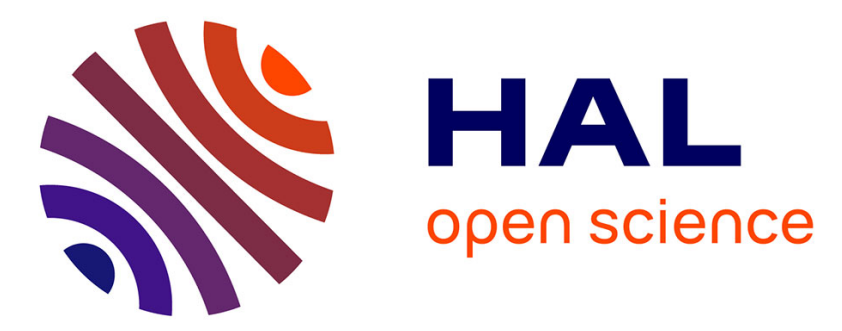

\title{
Influence of sintering methods on microstructure and ionic conductivity of La1.95Sr0.05Zr2O6.975 synthesized by co-precipitation
}

Da Huo, Dominique Gosset, David Siméone, Gianguido Baldinozzi, Hicham Khodja, Benjamin Villeroy, Suzy Surblé

\section{To cite this version:}

Da Huo, Dominique Gosset, David Siméone, Gianguido Baldinozzi, Hicham Khodja, et al.. Influence of sintering methods on microstructure and ionic conductivity of La1.95Sr0.05Zr2O6.975 synthesized by co-precipitation. Solid State Ionics, 2015, 278, pp.181-185. 10.1016/j.ssi.2015.05.028 . hal-01187785

\section{HAL Id: hal-01187785 \\ https://hal.science/hal-01187785}

Submitted on 1 Dec 2015

HAL is a multi-disciplinary open access archive for the deposit and dissemination of scientific research documents, whether they are published or not. The documents may come from teaching and research institutions in France or abroad, or from public or private research centers.
L'archive ouverte pluridisciplinaire HAL, est destinée au dépôt et à la diffusion de documents scientifiques de niveau recherche, publiés ou non, émanant des établissements d'enseignement et de recherche français ou étrangers, des laboratoires publics ou privés. 


\title{
Influence of sintering methods on microstructure and ionic conductivity of $\mathrm{La}_{1.95} \mathrm{Sr}_{0.05} \mathrm{Zr}_{2} \mathrm{O}_{6.975}$ synthesized by co-precipitation
}

\author{
Da Huo ${ }^{1,2}$, Dominique Gosset ${ }^{3}$, David Siméone ${ }^{2}$, Gianguido Baldinozzi ${ }^{2}$, Hicham Khodja ${ }^{1}$, \\ Benjamin Villeroy ${ }^{4}$, Suzy Surblé ${ }^{1}$ \\ ${ }^{1}$ CEA / IRAMIS / NIMBE / LEEL, F-91191 Gif-sur-Yvette, France. \\ CNRS / UMR 3299 / SIS2M / LEEL, F-91191 Gif-sur-Yvette, France. \\ 2 SPMS, LRC Carmen, CNRS and Ecole Centrale Paris, Châtenay-Malabry and \\ CEA/DEN/DANS/DMN/SRMA/LA2M-LRC CARMEN, Gif-sur-Yvette France. \\ ${ }^{3}$ CEA/DEN/DANS/DMN/SRMA/LA2M CEA Saclay, F-91191 Gif-sur-Yvette, France \\ ${ }^{4}$ Institut de Chimie et des Matériaux Paris Est (ICMPE), UMR 7182, 94320 Thiais, France
}

\begin{abstract}
:
We present here the synthesis of Sr-doped lanthanum zirconate pyrochlores $\mathrm{La}_{1.95} \mathrm{Sr}_{0.05} \mathrm{Zr}_{2} \mathrm{O}_{6.975}$ with controlled grain sizes and we compare different methods of sintering. Pyrochlores are systems where it is hard to achieve high density without a significant coarsening of the sample microstructure. It is shown that the use of Spark Plasma Sintering (SPS) can produce high density ceramic samples while maintaining a nanometric grain size, a key factor for enhancing electrical and mechanical properties. Furthermore, ionic conductivity is found higher in samples sintered using SPS than in those produced by hot pressing.
\end{abstract}

Keywords: Pyrochlore, Spark Plasma Sintering, Ionic conductivity, Hot pressing, Surface decomposition.

\section{Introduction}

Pyrochlore-based ceramics with the generic formula $\mathrm{A}_{2} \mathrm{~B}_{2} \mathrm{O}_{7}$ have become a very active field of research in the area of solid-state physics, chemistry, and engineering because of their wide variety of applications such as ionic conductors in fuel cells [1], immobilization of actinides materials in nuclear waste [2]-[3] and catalysis [4]. Mechanical and transport properties are strongly related to their microstructure, which in turn depends on the synthesis conditions. In principle, these materials can be synthesized by different methods, such as solid-solid, combustion [5], sol-gel [6], co-precipitation [7], molten-salt [8] or hydrothermal [9] methods. In the case of application as ionic conductors, high density materials have to be produced to allow a sound characterization of their properties by impedance spectroscopy. Some of the methods, such as uniaxial pressing, isostatic pressing or centrifugation, include a first packing step of the particles into green bodies and a second step of sintering in order to maximize densification. Other methods which simultaneously compact and sinter particles, such as spark plasma sintering and hot uniaxial pressing, have also been used to consolidate nanoceramics. Due to the refractory nature of the pyrochlore oxides, the choice of the densification method is fundamentally important because the prepared sample must attain the highest densification while keeping a reproducible microstructure.

The conductivity of a sample depends on many factors. Among the latters, the influence of different synthesis methods on ionic conductivity of aliovalent-doped ceria has been investigated by Kim et al. [10]. Marrero-López et al. [11] reported an effect of microstructure on the transport properties of apatite-type electrolyte. Other more specific impacts could be attributed to the grain size and the interparticle neck size [12] or the pore structure [13]. Moreover, high resistivity in the grain boundaries is observed for many ionic conductors and is commonly attributed to blocking impurity phases at the grain boundaries [14]. Different sample preparation processes may cause all of these factors leading in an increase in resistivity. 
Many researchers have studied the ionic conductivity of pyrochlore $\mathrm{A}_{2} \mathrm{~B}_{2} \mathrm{O}_{7}$ but comparison of collected data from different groups is not straightforward. Eurenius [15] made a significant contribution investigating of acceptor-doped $\mathrm{Sm}_{2} \mathrm{Sn}_{2} \mathrm{O}_{7-\delta}$ pyrochlores. However, the prepared pellets only had relative densities between $79-86 \%$ and the effect of the porosity was not investigated. Some ionic conductivities were sometimes presented without their relative density [16]. Furthermore, all these samples were prepared by solid-solid synthesis, followed by uniaxial pressing and high temperature sintering. This route is well-known for the problem of poor density and impurities. Therefore, a more thorough and detailed focus on the preparation processes is highly desired to understand the effect of sintering methods on the microstructure and thus ionic conductivity of pyrochlore ceramics. In this paper, we report the preparation and characterizations of $\mathrm{La}_{1.95} \mathrm{Sr}_{0.05} \mathrm{Zr}_{2} \mathrm{O}_{6.975}$ (hereafter noted LSZO), the doped material presents better properties for protonic conductivity under wet atmosphere [1] via co-precipitation method and compare the advantages and the drawbacks of several sintering techniques.

\section{Experimental}

LSZO powders were synthesized by a co-precipitation process. An aqueous solution of $\mathrm{La}\left(\mathrm{NO}_{3}\right)_{3} .6 \mathrm{H}_{2} \mathrm{O}\left(99.999 \%\right.$, Aldrich), $\mathrm{Sr}\left(\mathrm{NO}_{3}\right)_{2}\left(99 \%\right.$, Aldrich) and $\mathrm{ZrOCl}_{2} .8 \mathrm{H}_{2} \mathrm{O}$ (99.5\%, Aldrich) was prepared according to a stoichiometric mixture of the starting products. Then oxalic acid (Normapur, Prolabo) was slowly added to the mixed solution (oxalic acid:zirconium $=4: 1$ ) leading to LSZO precursors precipitation. Then, the precipitate was dried at $90^{\circ} \mathrm{C}$. The final material was obtained by calcination of the dried oxalate precipitates at different temperatures. X-ray diffraction powder patterns of the products were recorded at room temperature using a diffractometer equipped with a Curved Position Sensitive Detector (INEL CPS -120) using the monochromatic $\mathrm{Cu}-\mathrm{K}_{\alpha 1}$ radiation $(1.54059 \AA)$. Rietveld refinements were carried out using the XND program [17][18].

In order to obtain high compactness pellets with maintaining nanosized grains, different sintering methods were tested: (i) uniaxial pressing (UP) under $250 \mathrm{MPa}$ at room temperature followed by sintering at different temperatures between $800^{\circ} \mathrm{C}$ and $1500^{\circ} \mathrm{C}$, (ii) hot-pressing (HP) sintering by using a WC die in a furnace at $700^{\circ} \mathrm{C}$ under uniaxial pressing at $250 \mathrm{MPa}$, and (iii) spark plasma sintering (SPS) by using a graphite die, preheating at $600^{\circ} \mathrm{C}$ followed by a second heating step under $100 \mathrm{MPa}$ at $1200^{\circ} \mathrm{C}$ and $1500^{\circ} \mathrm{C}$. Graphite foils (Papyex ${ }^{\circledR}$ ) were also used to prevent direct contact between graphite parts and the specimens. We present in this paper the sintering results obtained only with the starting powder at $800^{\circ} \mathrm{C}$.

Elemental analyses of pellet cross-section were performed using the nuclear microprobe at IRAMIS/LEEL at CEA-Saclay. A $3 \mathrm{MeV}$ alpha beam was used to probe the samples and several techniques such as RBS (Rutherford Backscattering Spectroscopy) and PIXE (Particle-Induced X-ray Emission) were used in order to determine the elemental concentrations [19]. The microstructure of the materials was characterized by scanning electron microscopy (SEM-FEG) using a Zeiss GEMINI 1525 apparatus. The ionic conductivity was measured via a two-point measurement by using Materials Mates 7260 impedancemeter. The frequency range is $6 \mathrm{MHz}-0.1 \mathrm{~Hz}$ and a $100 \mathrm{mV}$ amplitude was applied. Au electrodes were sputtered on both sides of the sample.

\section{Results and discussion}

\subsection{Structure evolution}

Powders calcined at $800^{\circ} \mathrm{C}$ have a single phase of C-type fluorite structure; while samples calcined at $1500^{\circ} \mathrm{C}$ present a pyrochlore structure, which is characterized by the presence of typical superlattice diffraction peaks at $2 \theta$ values about $14.2^{\circ}(111), 27.3^{\circ}(311), 36^{\circ}(331), 43.5^{\circ}$ (511) and $49.8^{\circ}$ (531) [7][20]. For example, the comparison between XRD patterns of LSZO calcined at $800^{\circ} \mathrm{C}$ and $1500^{\circ} \mathrm{C}$ is shown on Figure 1a. The pyrochlore structure is centrosymmetric (space group $F d-3 m$, origin on the $\mathrm{Zr}$ site at $-3 m$ ). The La cations are located on the $16 d$ Wyckoff positions $(1 / 2,1 / 2,1 / 2)$ surrounded by eight oxygen atoms, while the $\mathrm{Zr}$ atoms are located on the $16 c$ site $(0,0,0)$ in octahedral environment. Strontium is assumed to be located on the $16 d$ Wyckoff positions in substitution of the 
lanthanum atoms. The oxygen atoms are located on the $8 b(3 / 8,3 / 8,3 / 8)$ and $48 f(\mathrm{u}, 1 / 8,1 / 8)$ sites. Most commonly, cubic pyrochlores could be considered as a fluorite-type structure with a double unit cell and an ordered deficiency of $1 / 8$ of the oxygen atoms, as shown in Figure $1 \mathrm{~b}$. The structures of the intermediate temperature $\left(900^{\circ} \mathrm{C}-1400^{\circ} \mathrm{C}\right)$ calcined powder are refined using both C-type fluorite and pyrochlore structures. The Rietveld refinements were in good agreement with literature (see Table 1). [21] From the Williamson-Hall analysis, after correcting the instrumental broadening, the crystallite size was estimated at about $74 \mathrm{~nm}$ for LSZO.

\subsection{Characteristics of sintered samples}

The uniaxial pressing (UP) compacted a green body less than $50 \%$ of their relative density. After a long time sintering up to $1500^{\circ} \mathrm{C}$, pellets with very low compactness (only $62 \%$ ) were systematically produced. To access to higher densification, an annealing at high temperature was required but an increase of the grain size was unavoidable. Moreover, XRD experiments showed extra phases after the sintering step (Figure 2a). Some additional peaks appeared when the LSZO pellet prepared by UP was sintered at $1500^{\circ} \mathrm{C}$ ( 4 hours), while the as-synthesized material exhibited a single phase. One of these peaks could be attributed to $\mathrm{SrZrO}_{3}$ phase. But after a polishing step of the pellet surface, XRD experiment showed the original pyrochlore structure, suggesting a decomposition of LSZO at the surface. In order to confirm this fact, elemental maps ( $\mathrm{La}, \mathrm{Zr}$ and $\mathrm{Sr}$ ) were obtained by nuclear microprobe and the relative concentrations of the elements were found coherent with the pyrochlore structure and $\mathrm{SrZrO}_{3}$ phases on pellet surface, as can be seen on Figure 2b. Gomann et al. suggested $\mathrm{Sr}$ diffusion in La-doped $\mathrm{SrTiO}_{3}$ single crystals between $1250^{\circ} \mathrm{C}$ and $1500^{\circ} \mathrm{C}$ [22]. Meyer observed a $\mathrm{SrO}_{x}$ surface segregation in donor-doped $\mathrm{SrTiO}_{3}$ under oxidizing conditions [23]. They proposed a mechanism where $\mathrm{Sr}$ vacancies and $\mathrm{SrO}$ complexes are formed at the surface at temperatures below $1000^{\circ} \mathrm{C}$ followed by $\mathrm{Sr}$ vacancies diffusion into the crystal which result in an accumulation of $\mathrm{SrO}$ at the surface at higher temperatures. The mechanism in our case is not elucidated here and it is still under investigation.

The relative density obtained by the hot pressing process (HP) with the starting powder at $800^{\circ} \mathrm{C}$ was not enough (61\%). Moreover the fluorite structure was maintained. To improve the compactness, an annealing step at $1500^{\circ} \mathrm{C}$ was performed. However, such a density (78\%) is still too low for further characterization by impedance spectrscopy. Moreover, the same decomposition phenomenon occured at the pellet's surface. At last, a significant improvement of the relative density was obtained with the SPS process $\left(95 \%\right.$ at $1500^{\circ} \mathrm{C}$, Figure 3a), this within a total preparation time of 1 hour $(15 \mathrm{~min}$ under $100 \mathrm{MPa}$ at $1500^{\circ} \mathrm{C}$ ). For example, the inset of the Figure 3a shows the linear shrinkage of the sample during SPS sintering. According to the derivative curve, shrinkage takes place around $1100^{\circ} \mathrm{C}$ and is achieved at $1480^{\circ} \mathrm{C}$, this temperature corresponds to a complete densification of the material. Furthermore, the pyrochlore structure was obtained in few minutes for both sintering processes $\left(1200^{\circ} \mathrm{C}\right.$ and $\left.1500^{\circ} \mathrm{C}\right)$ without parasitic phases (Figure $3 \mathrm{~b}$ ).

The obtained experimental data clearly show that the SPS process enhances both densification and grain growth. According to the Rietveld analyses of each pellet's diagram, the influence of sintering temperature on crystallite size is plotted in Figure 4, where the crystallite sizes are calculated using the Williamson-Hall method. The SPS method appears here as the best way to sinter the material without significantly growing the particle size, here around $120 \mathrm{~nm}$ after sintering at $1500^{\circ} \mathrm{C}$. Morphology has been analyzed from Scanning Electron Microscope (SEM). Although the particle sizes observed by SEM were slightly higher than the crystallite size from XRD, the grain sizes were in nanometer range. The morphology of pellets appeared similar except for the pellet sintered by HP at $1500^{\circ} \mathrm{C}$, where its particles were agglomerated.

Electrical properties are often dependent on the characterization of grain boundaries (morphology, crystallinity,...) and crystallite size is generally a parameter that influences those characteristics. The difference between crystallite size and particle size in a nanoparticle can account for amorphous grain boundaries and provide an estimate for the width of this region that has a specific influence on electrical properties. 


\subsection{Ionic conductivity}

Due to the low relative density of UP pellets, only HP and SPS pellets were investigated by impedance spectroscopy. Figure 5 shows the Nyquist impedance plots of LSZO prepared by HP and SPS processes. The HP pellet has been polished so that all of the impurities produced by surface decomposition have been removed. The experimental points were fitted by a least squares procedure using an equivalent circuit composed of a serie of (R \| CPE) in order to determine electrical parameters of the LSZO ceramics. $\mathrm{R}$ is a pure resistance and CPE is a Constant-Phase Element. The complex impedance of these contributions is given by Equation (1)

$Z_{R}=R \quad Z_{C P E}=\frac{1}{Q(j \omega)^{p}}$

where $\mathrm{Q}$ is the module of the $\mathrm{CPE}$ and $p$ a parameter taking account of the depression of the semi circle. For HP pellet, three (R $\| \mathrm{CPE}$ ) were required for the simulation of the Nyquist plots, taking into account contributions of bulk, grain boundary and electrode. Only two time constants could be observed for SPS pellet. The time constant at high frequencies can be attributed to the bulk conduction and at the lowest frequencies the electrode processes is observed. The grain boundary contribution is not separated from the bulk one. Hence, the equivalent circuit used to fit these data consists of two (R \| CPE) in series. The effective capacitance $\mathrm{C}$ and the dielectric constant $\varepsilon$ ' were calculated after correcting for the frequency dispersion according to Equation (2)

$C=R^{\left(\frac{1-p}{p}\right)} Q^{\left(\frac{1}{p}\right)} \quad$ then $\varepsilon^{\prime}=\frac{C d}{\varepsilon_{0} A}$

where $\varepsilon_{0}$ is the constant of permittivity of free space, $\mathrm{d}$ and A correspond to sample geometry of the pellet (i.e. thickness of the pellet and cross sectional area respectively). The capacitances associated with bulk conduction were found to be $4.20(1) \cdot 10^{-10} \mathrm{~F}$ and $4.52(1) \cdot 10^{-10} \mathrm{~F}$ for respectively the HP and SPS sintering processes. The dielectric constants determined from these capacitance values were 1051.8(6) and 1995.2(2). These values were in good agreement with the values determined for the $\mathrm{V}-\mathrm{Ge}$ doped lanthanum zirconate $\left(\varepsilon^{\prime}=1530\right)$ [24].

The bulk and macroscopic grain boundary conductivities could be calculated by taking into account the resistances of bulk, grain boundary and the sample geometry (Table 2). According to the Arrhenius plots of specific conductivities for bulk and grain boundary (Figure 6), the activation energy is nearly independent on the sintering processes. Our values $(1.07 \mathrm{eV}$ for the HP pellet and $1.00 \mathrm{eV}$ for the SPS pellet) were similar to the literature. Hagiwara et al. have reported an activation energy of $1.03 \mathrm{eV}$ for the non-doped $\mathrm{La}_{2} \mathrm{Zr}_{2} \mathrm{O}_{7}$ sample [25]. Whereas an increase of $0.23 \mathrm{eV}$ the activation energy was observed for $\mathrm{Ca}$ substituted $\mathrm{La}_{2} \mathrm{Zr}_{2} \mathrm{O}_{7}$ materials [26].

The specific conductivity of bulk for HP pellet is much lower compared with SPS pellet. Two reasons should be considered. The porosity can be corrected according to the equation proposed by Vischjager et al.[27], which could be written as:

$\sigma=\sigma_{0}(1-P)^{x}$

Where $\sigma$ is the measured conductivity, $\sigma_{0}$ conductivity at theoretical density and $\mathrm{P}$ the porosity. The parameter $\mathrm{x}$ could range between 1.5 and 2 . Whatever the value of $\mathrm{x}$, this equation indicates that the conductivity decreases with the increase of porosity. Further studies of pellets with different porosities prepared by SPS process are in progress to better understand the influence of porosity and get rid of the variation of substitution element concentration. Here, the ionic conductivity of $78 \%$ sample is three orders of magnitude lower than expected value. Furthermore, it is well-known that the high oxygen vacancy concentration could result in a high oxygen-ion mobility [28]. In general, the substitution of $\mathrm{Sr}$ create oxygen vacancies by charge compensation according to the following equation expressed by Kroger-Vink notation: 


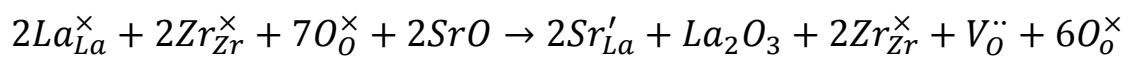

As pointed out in the previous section, the decomposition phenomenon and accumulation of $\mathrm{Sr}$ at the pellet surface has also been observed for pellet $\mathrm{HP}$ after an annealing at $1500^{\circ} \mathrm{C}$. The formation and accumulation of $\mathrm{SrZrO}_{3}$ on pellet's surface decrease the concentration of substitution in the bulk and therefore decrease the oxygen vacancies and thus increases the bulk resistance.

The sintering processes not only affect the bulk conductivity but also the response of grain boundary. An obvious contribution of grain boundary is visible for HP sintering process. Considering the possibility of diffusion of $\mathrm{Sr}$ and decomposition, the appearance of this contribution could be attributed to the impurities accumulation residing at the grain boundaries after long time annealing at $1500^{\circ} \mathrm{C}$. It is worth to mention that the contribution of grain boundary becomes invisible by SPS sintering method. It should be noted that Chen [29] also reported an improvement of grain boundary resistivity by using SPS sintering. It was reported that the SPS could form clean grain boundaries because of the surface-cleaning effect [30]. This improvement of property could also be attributed to the short duration of SPS sintering process which produces a homogeneous microstructure and composition and prohibits excessive grain growth and segregation of impurities at the grain boundary in our pellet prepared by SPS.

\section{Conclusions}

We have studied the ability of different sintering processes to produce dense samples of pure and strontium-substituted pyrochlore $\mathrm{La}_{1.95} \mathrm{Sr}_{0.05} \mathrm{Zr}_{2} \mathrm{O}_{6.975}$ materials displaying nanometric crystallite sizes (74-200 nm range). The initial powders were produced using the coprecipitation route. Cold uniaxial pressing systematically fails to produce high density green bodies. As a consequence, sample annealing at high temperature produce ceramics with nanometric grain sizes but with a lot of residual open porosities. Annealing at $1500^{\circ} \mathrm{C}$ increases the density of the ceramic samples but also leads to surface decomposition of LSZO and to the formation of $\mathrm{SrZrO}_{3}$. Uniaxial hot pressing at temperatures up to $700^{\circ} \mathrm{C}$ also fails at producing dense samples with the desired nanostructure. Conversely the SPS method allows a nearly full densification of the material without decomposition or formation of parasitic phases. Moreover, the reduced dwell time of SPS also minimizes the growth of the particle size. AC impedance spectroscopy studies reveal the influence of sintering processes on not only the bulk conductivity but also the grain boundary conductivity. The material sintered by SPS shows higher bulk conductivity and no independent contributions of grain boundary. Spark plasma sintering is a promising and effective method to sinter the nanostructured pyrochlore ceramics. In conclusion, samples produced by SPS display the highest density and very reproducible nanostructures that are compatible with the mechanical and electrical requirements of the envisioned applications for nuclear waste management or as an electrolyte layer in fuel cells and gas detectors.

\section{Acknowledgement}

The authors thank Mr. Patrick Bonnaillie and Mme Sylvie Poissonnet for SEM-FEG micrographs.

\section{References}

[1] T. Shimura, M. Komori, H. Iwahara, Solid State Ion. 86-88, Part 1 (1996) 685.

[2] R.C. Ewing, W.J. Weber, J. Lian, J. Appl. Phys. 95 (2004) 5949.

[3] Y.H. Li, B.P. Uberuaga, C. Jiang, S. Choudhury, J.A. Valdez, M.K. Patel, J. Won, Y.-Q. Wang, M. Tang, D.J. Safarik, D.D. Byler, K.J. McClellan, I.O. Usov, T. Hartmann, G. Baldinozzi, K.E. Sickafus, Phys. Rev. Lett. 108 (2012) 195504.

[4] J.M. Sohn, S.I. Woo, Catal. Lett. 79 (2002) 45.

[5] Y. Tong, S. Zhao, W. Feng, L. Ma, J. Alloys Compd. 550 (2013) 268.

[6] K. Shimamura, T. Arima, K. Idemitsu, Y. Inagaki, Int. J. Thermophys. 28 (2007) 1074. 
[7] D. Prusty, A. Pathak, A. Chintha, B. Mukherjee, A. Chowdhury, J. Am. Ceram. Soc. 97 (2014) 718.

[8] M.L. Hand, M.C. Stennett, N.C. Hyatt, J. Eur. Ceram. Soc. 32 (2012) 3211.

[9] C. Wang, Y. Wang, Y. Cheng, W. Huang, Z.S. Khan, X. Fan, Y. Wang, B. Zou, X. Cao, J. Mater. Sci. 47 (2012) 4392.

[10] G. Kim, N. Lee, K.-B. Kim, B.-K. Kim, H. Chang, S.-J. Song, J.-Y. Park, Int. J. Hydrog. Energy 38 (2013) 1571.

[11] D. Marrero-López, L. dos Santos-Gómez, L. León-Reina, J. Canales-Vázquez, E.R. Losilla, J. Power Sources 245 (2014) 107.

[12] F. Zhao, A.V. Virkar, J. Power Sources 195 (2010) 6268.

[13] D. Wiedenmann, L. Keller, L. Holzer, J. Stojadinović, B. Münch, L. Suarez, B. Fumey, H. Hagendorfer, R. Brönnimann, P. Modregger, M. Gorbar, U.F. Vogt, A. Züttel, F.L. Mantia, R. Wepf, B. Grobéty, AIChE J. 59 (2013) 1446.

[14] C. Kjølseth, H. Fjeld, Ø. Prytz, P.I. Dahl, C. Estournès, R. Haugsrud, T. Norby, Solid State Ion. 181 (2010) 268.

[15] K.E.J. Eurenius, E. Ahlberg, C.S. Knee, Solid State Ion. 181 (2010) 1577.

[16] W. Sun, S. Fang, L. Yan, W. Liu, Fuel Cells 12 (2012) 457.

[17] J.-F. Berar, G. Baldinozzi, IUCr-CPD Newsl. (1998) 3.

[18] D. Simeone, G. Baldinozzi, D. Gosset, G. Zalczer, J.-F. Berar, J. Appl. Crystallogr. 44 (2011) 1205.

[19] O. Bohnke, S. Lorant, M. Roffat, P. Berger, Solid State Ion. 262 (2014) 563.

[20] Z.-G. Liu, J.-H. Ouyang, Y. Zhou, J. Xiang, X.-M. Liu, Mater. Des. 32 (2011) 4201.

[21] M. Subramanian, G. Aravamudan, G. Rao, Prog. Solid State Chem. 15 (1983) 55.

[22] K. Gömann, G. Borchardt, M. Schulz, A. Gömann, W. Maus-Friedrichs, B. Lesage, O. Kaïtasov, S. Hoffmann-Eifert, T. Schneller, Phys. Chem. Chem. Phys. 7 (2005) 2053.

[23] R. Meyer, R. Waser, J. Helmbold, G. Borchardt, J. Electroceramics 9 (2002) 101.

[24] M.A. Farid, M.A. Asghar, M.N. Ashiq, M.F. Ehsan, M. Athar, Mater. Res. Bull. 59 (2014) 405.

[25] T. Hagiwara, K. Nomura, H. Yamamura, Solid State Ion. 262 (2014) 551.

[26] Q.A. Islam, S. Nag, R.N. Basu, Mater. Res. Bull. 48 (2013) 3103.

[27] D.J. Vischjager, A.A. van Zomeren, J. Schoonman, I. Kontoulis, B.C.H. Steele, Solid State Ion. 40-41, Part 2 (1990) 810.

[28] N.Q. Minh, J. Am. Ceram. Soc. 76 (1993) 563.

[29] X.J. Chen, K.A. Khor, S.H. Chan, L.G. Yu, Mater. Sci. Eng. A 374 (2004) 64.

[30] K.H. Kim, S.H. Shim, K.B. Shim, K. Niihara, J. Hojo, J. Am. Ceram. Soc. 88 (2005) 628 


\section{Figure captions}

Figure 1. Rietveld refinement for LSZO powders (a) at $800^{\circ} \mathrm{C}$ and (b) at $1500^{\circ} \mathrm{C}$. Schematic drawings comparing the arrangements of cations (left) and anions (right) in the unit cells of pyrochlore $\left(\mathrm{A}_{2} \mathrm{~B}_{2} \mathrm{O}_{7}\right)$ and fluorite $\left(\mathrm{MO}_{2}\right)$ compounds (lattice parameters $\left.=\mathrm{a}\right)$ were represented in insets. Only one octant of the pyrochlore unit cell was shown.

Figure 2. (a) XRD diagrams for LSZO powder annealed at $1500^{\circ} \mathrm{C}$ 4h (black), pellet prepared by UP sintered at $1500^{\circ} \mathrm{C} 4 \mathrm{~h}$ (red), pellet after polishing (blue); (b) Elemental maps obtained by nuclear microprobe on an UP cross-section pellet. The green line in maps represents the non-polished surface of the pellet.

Figure 3. (a) Relative densities for LSZO pellets prepared by different sintering processes. Linear shrinkage curve (black line) versus temperature for LSZO pellet at 100MPa and its derivative curve (red line) were represented in inset for the pellet sintered by SPS at $1500^{\circ} \mathrm{C}$. (b) Rietveld refinement for LSZO sample sintered by SPS at $1200^{\circ} \mathrm{C}$ under $100 \mathrm{MPa}$ pressure. For better visualization the data had been connected by a line.

Figure 4. Evolution of the crystallite size with sintering temperature of the samples LSZO, as deduced from Rietveld analysis of X-Ray diffraction diagrams. SEM micrographs are shown as insets.

Figure 5. Nyquist plot of impedance spectra for $\mathrm{La}_{1.95} \mathrm{Sr}_{0.05} \mathrm{Zr}_{2} \mathrm{O}_{6.975}$ at $740^{\circ} \mathrm{C}$ prepared (a) by hot pressing process ( $78 \%$ of relative density) (b) by SPS $1500^{\circ} \mathrm{C}$ ( $95 \%$ of relative density). The equivalent circuit used is shown in the inset of each figure.

Figure 6. Arrhenius plots of bulk conductivity for SPS pellet (95\%) and bulk and grain boundary conductivity for HP pellet (78\%). 


\section{Table captions}

Table 1. Crystal data and structure refinement parameters for $\mathrm{LSZO}$ at $800^{\circ} \mathrm{C}$ (fluorite) and $1500^{\circ} \mathrm{C}$ (pyrochlore).

Table 2. Bulk conductivity $\left(\sigma_{\text {bulk }}\right)$ and macroscopic grain boundary conductivity $\left(\sigma_{\mathrm{gb}}\right)$ of LSZO HP and SPS samples. 


\section{Highlights}

- Sr-doped lanthanum zirconates were prepared by co-precitation route.

- Only SPS processes allows full densification of materials

- Conductivies of $\mathrm{La}_{1.95} \mathrm{Sr}_{0.05} \mathrm{Zr}_{2} \mathrm{O}_{7-\delta}$ pyrochlores in air 


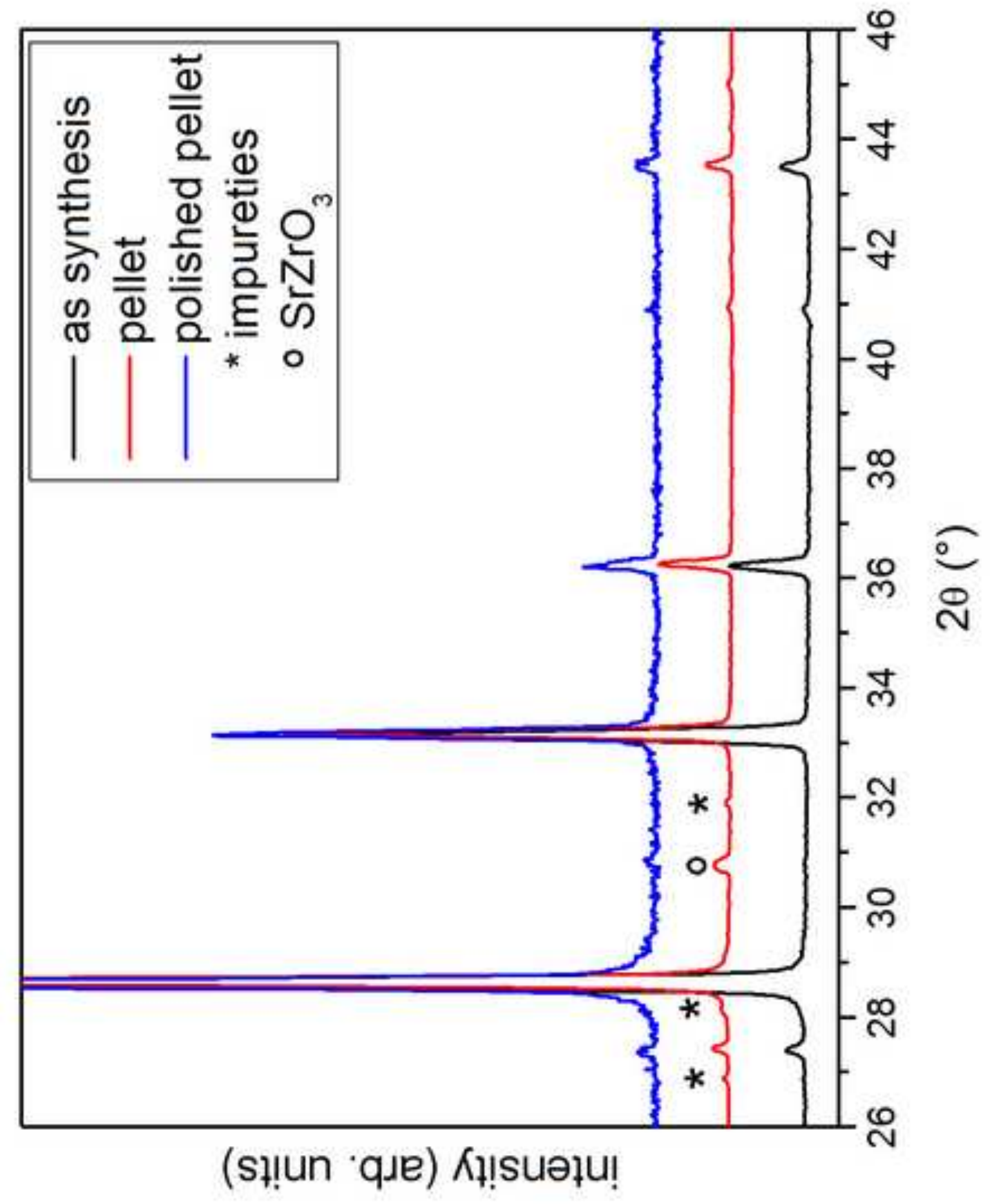




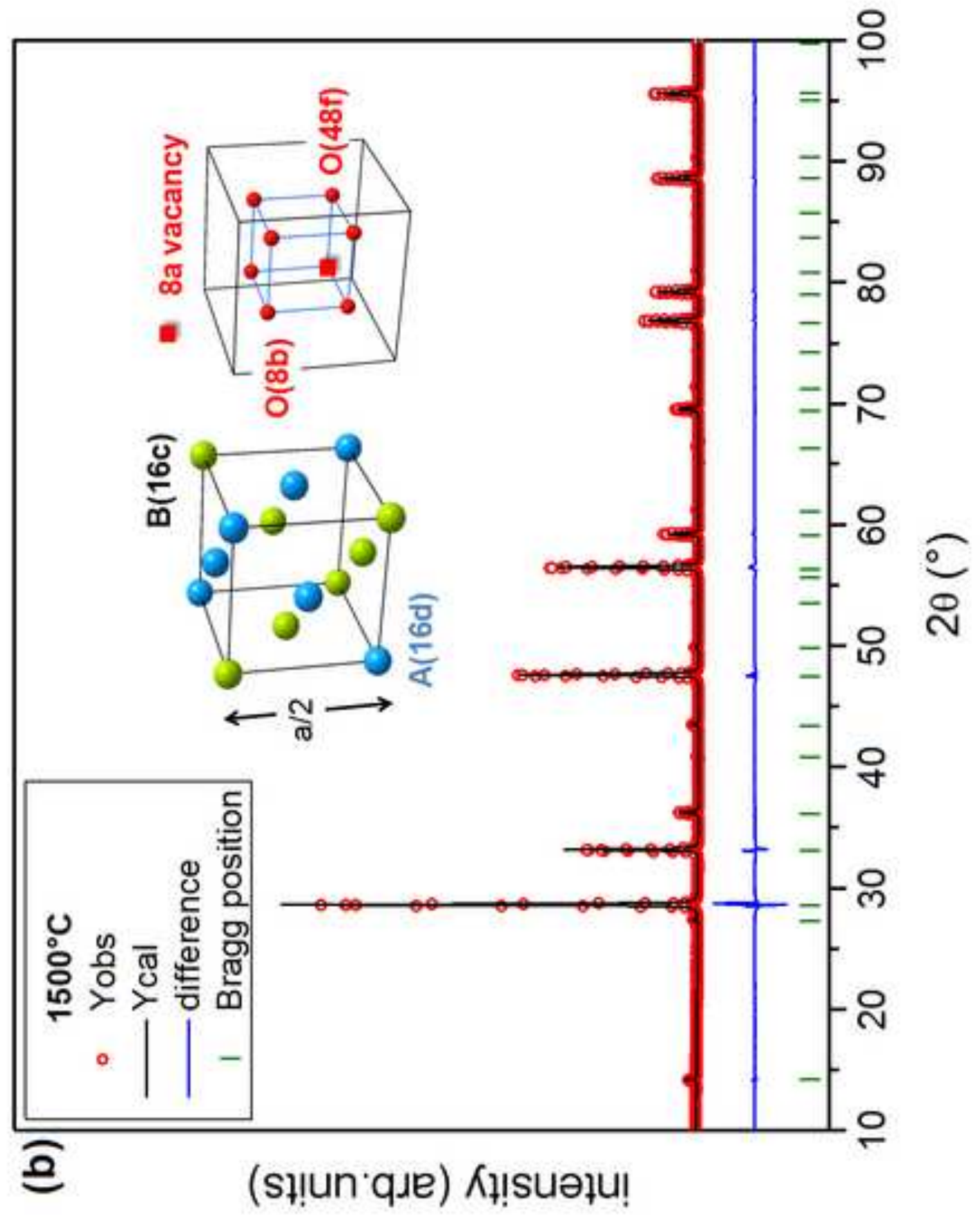




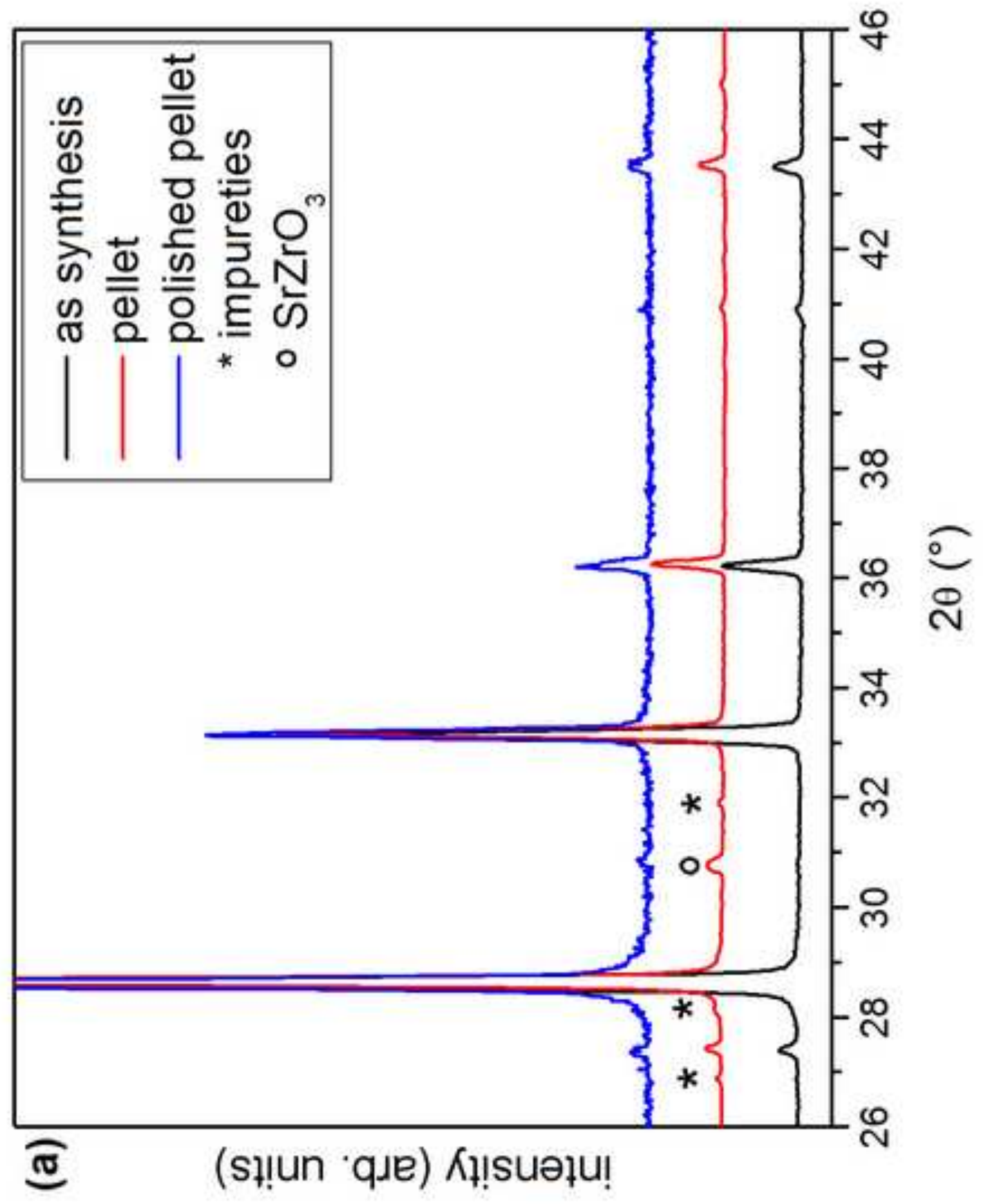



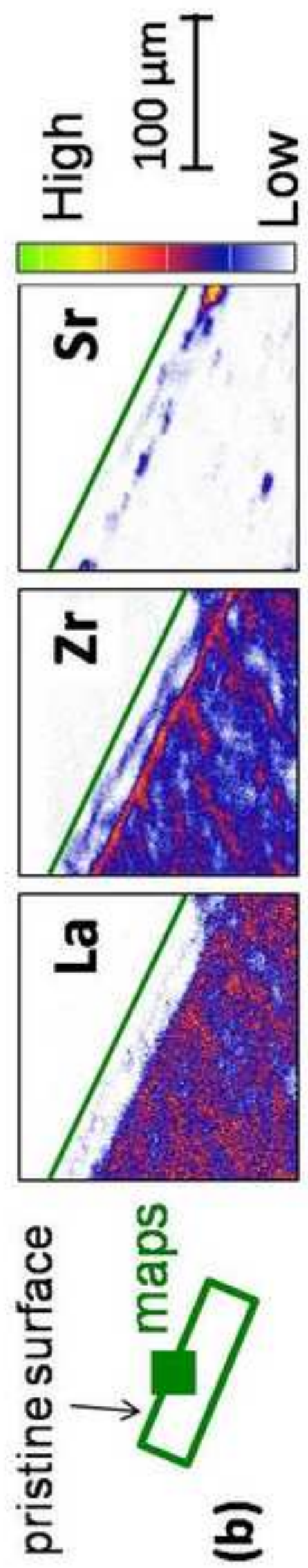

원

ఏ 은 둔

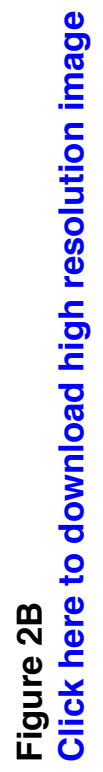




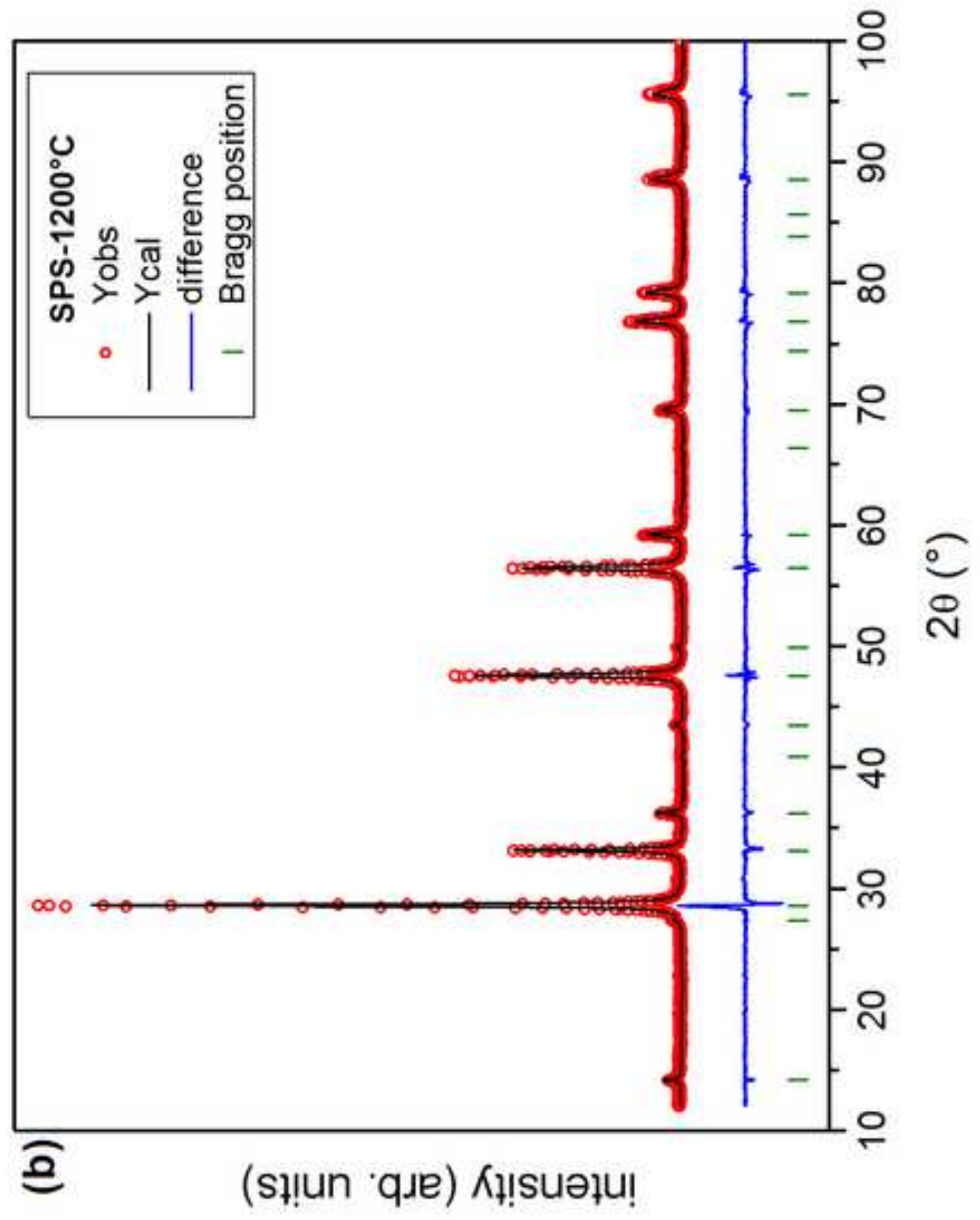




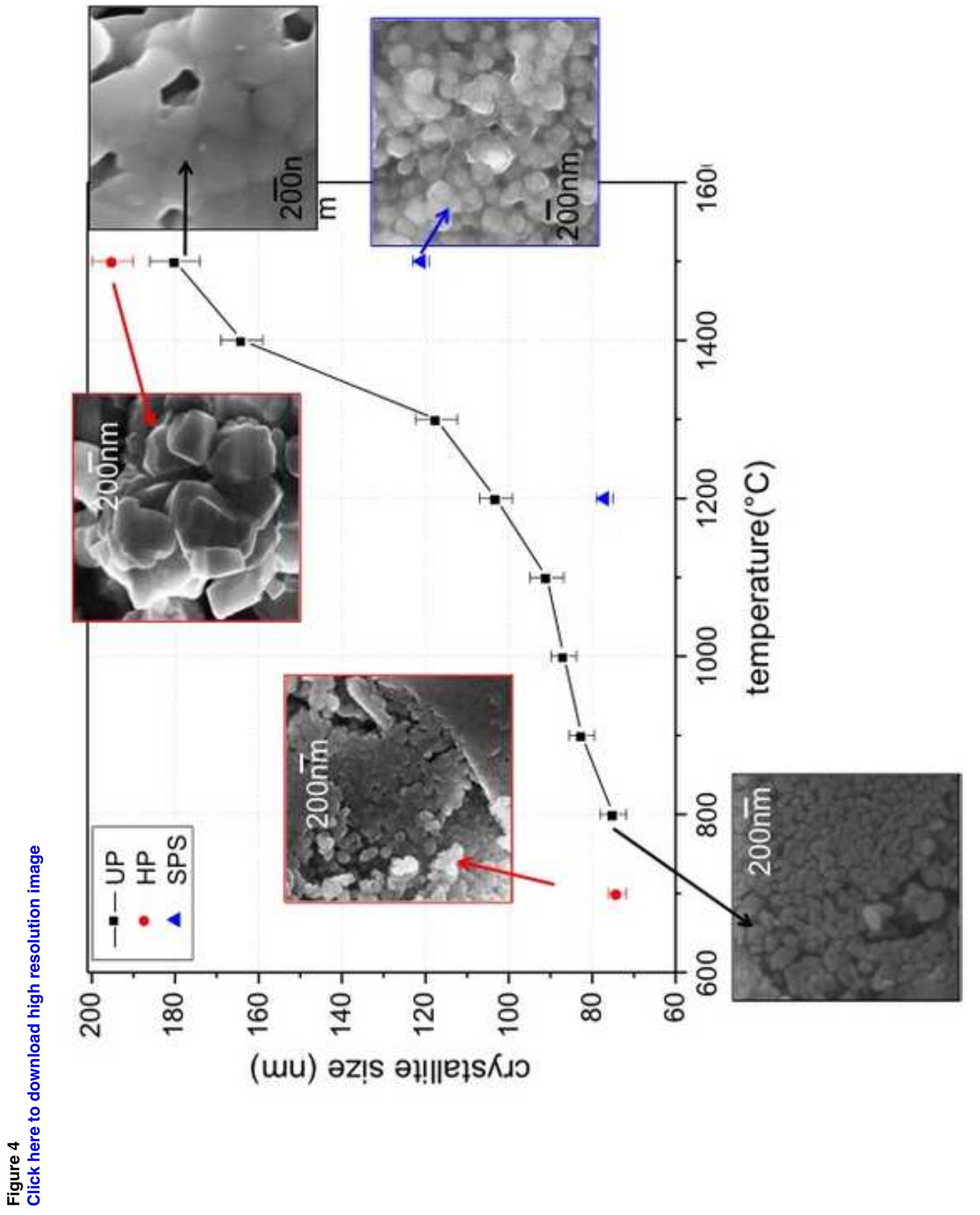




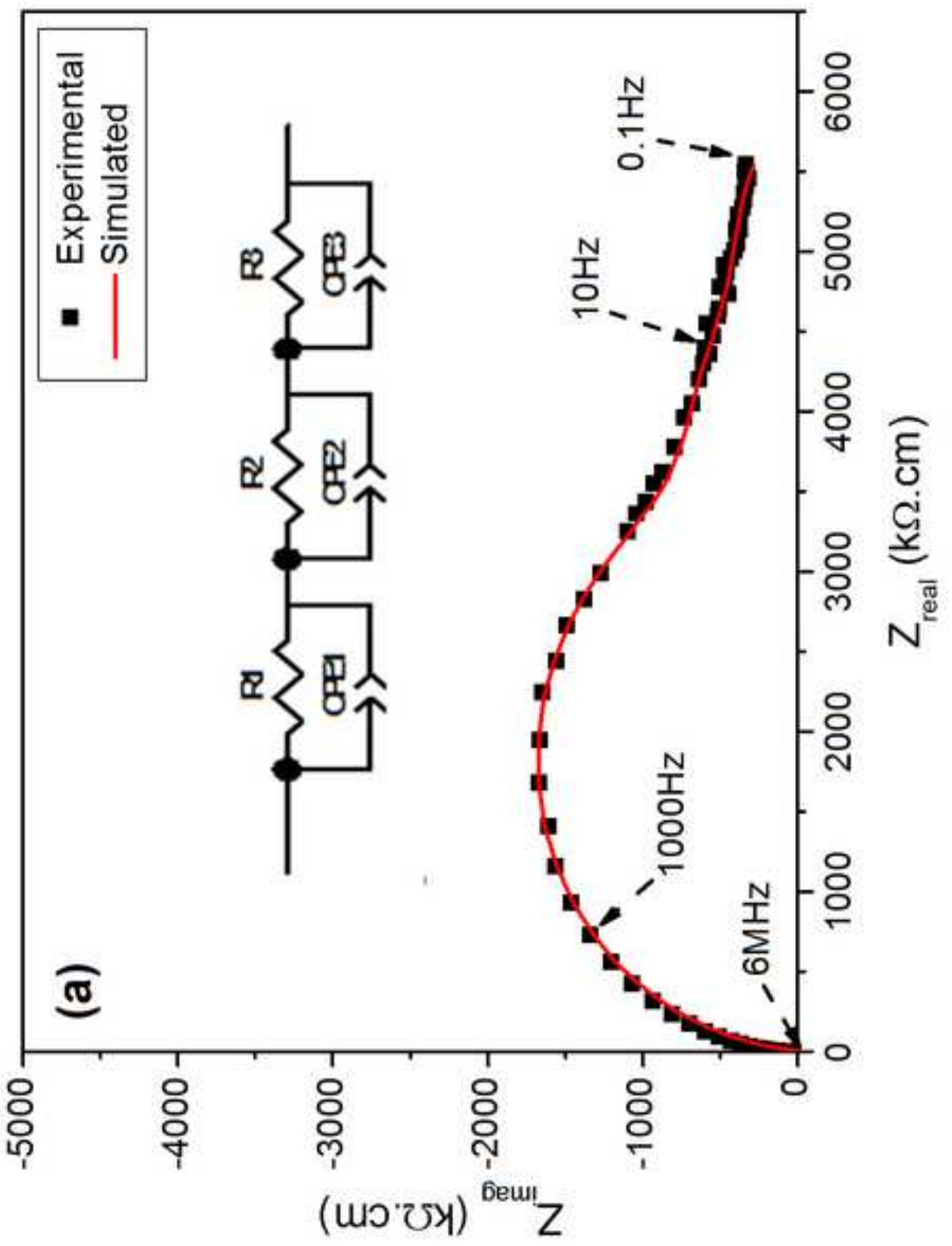




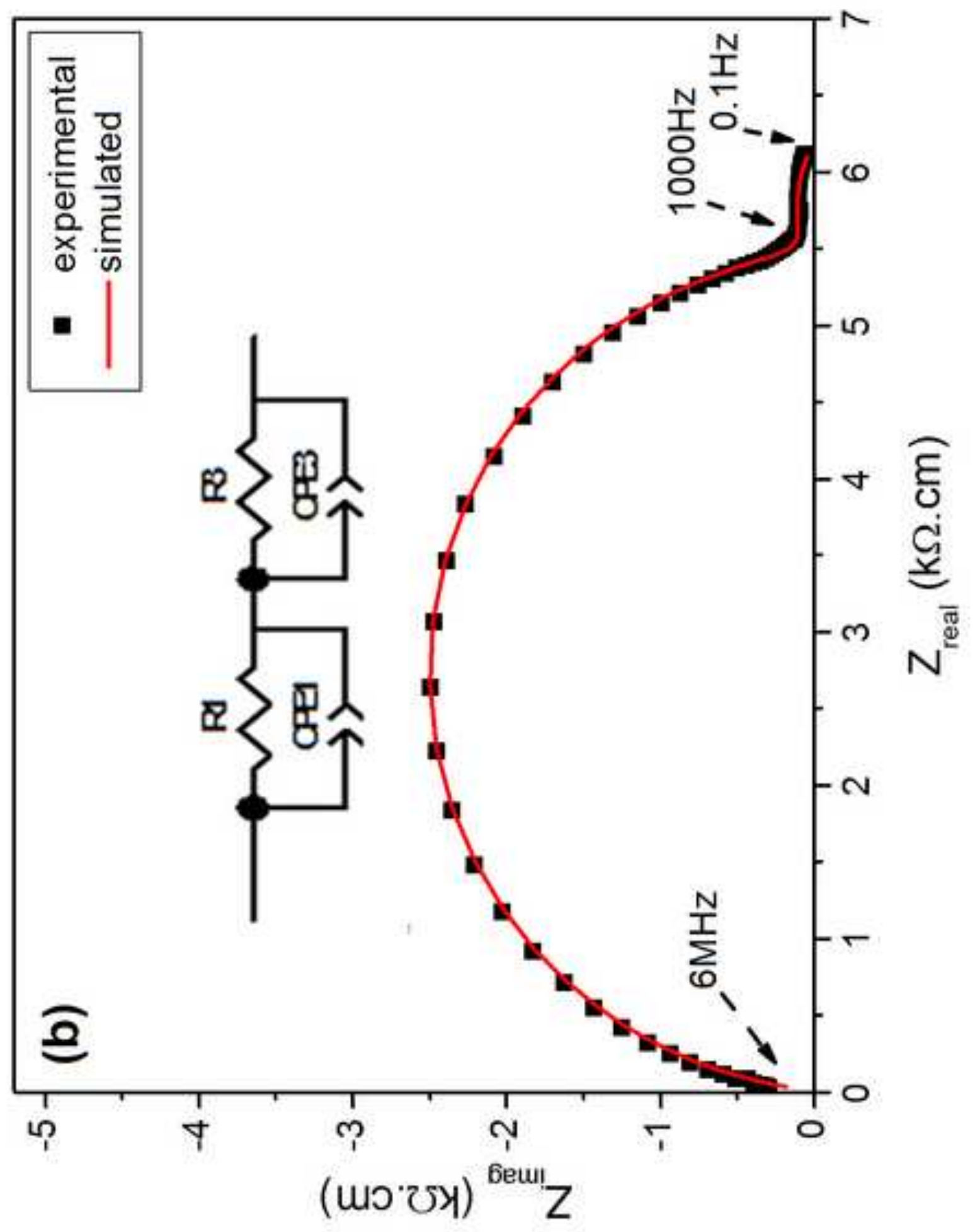




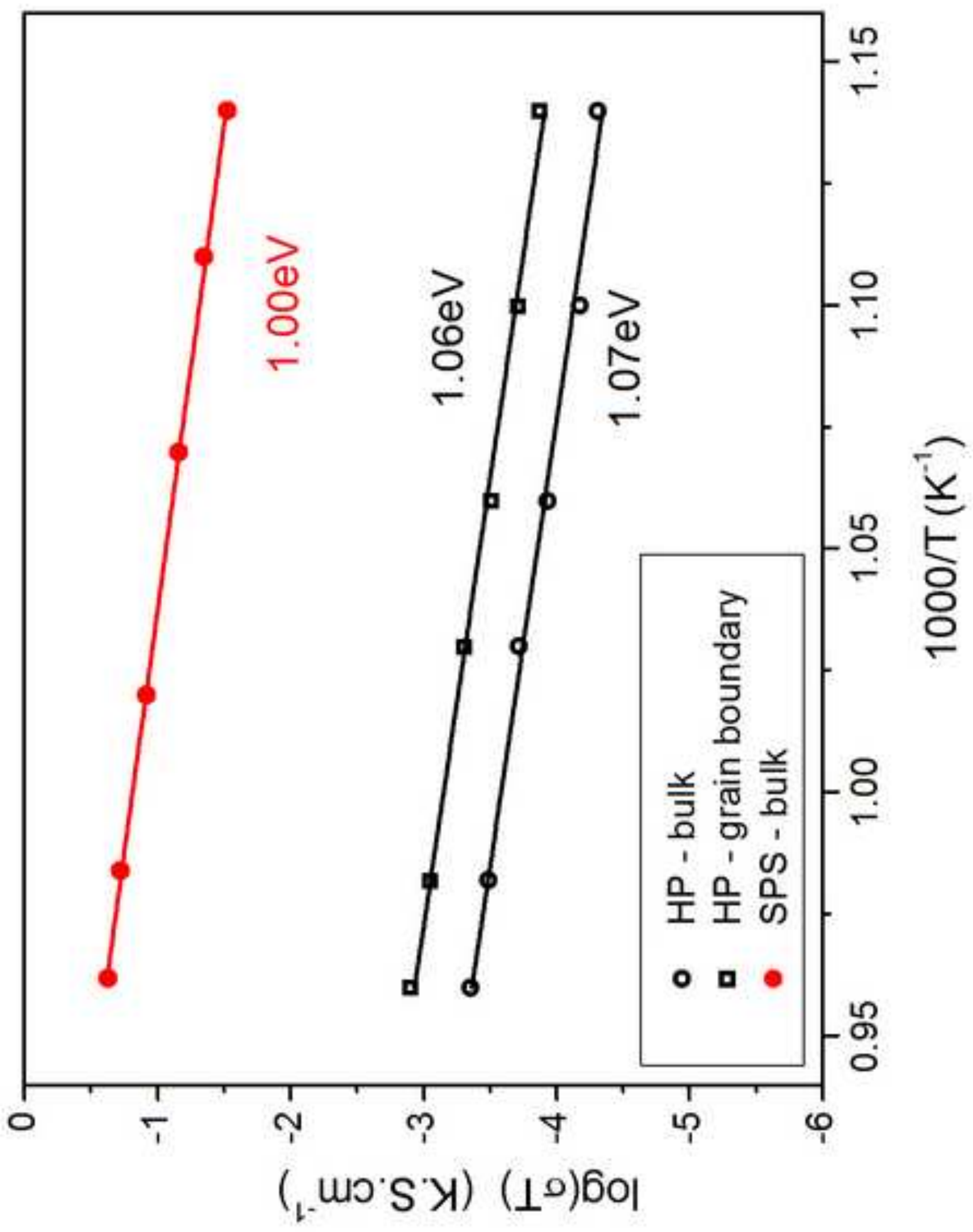


Table 1: Crystal data and structure refinement parameters for LSZO at $800^{\circ} \mathrm{C}$ (fluorite) and $1500^{\circ} \mathrm{C}$ (pyrochlore).

\begin{tabular}{|l|c|c|}
\hline & $\mathbf{L S Z O}-\mathbf{8 0 0}^{\circ} \mathbf{C}$ & ${\mathbf{L S Z O}-\mathbf{1 5 0 0}^{\circ} \mathbf{C}}$ \\
\hline cell parameter a $(\stackrel{\circ}{)})$ & $5.4014(4)$ & $10.8068(4)$ \\
\hline oxygen position u & - & $0.3321(4)$ \\
\hline $\mathbf{R}_{\text {Bragg }}$ & $5.60 \%$ & $5.52 \%$ \\
\hline
\end{tabular}


Table 2. Bulk conductivity ( $\square_{\text {bulk }}$ ) and macroscopic grain boundary conductivity ( $\square_{\mathrm{gb}}$ ) of LSZO HP and SPS samples.

\begin{tabular}{|c|c|c|c|c|}
\hline \multirow{2}{*}{ Sample } & \multicolumn{2}{|c|}{$\mathbf{7 4 0}^{\circ} \mathbf{C}$} & \multicolumn{2}{c|}{$\mathbf{6 0 0}^{\circ} \mathbf{C}$} \\
\cline { 2 - 5 } & $\square_{\text {bulk }}(\mathrm{S} / \mathrm{cm})$ & $\square_{\mathrm{gb}}(\mathrm{S} / \mathrm{cm})$ & $\square_{\text {bulk }}(\mathrm{S} / \mathrm{cm})$ & $\square_{\mathrm{gb}}(\mathrm{S} / \mathrm{cm})$ \\
\hline LSZO HP & $3.18 \times 10^{-7}$ & $8.16 \times 10^{-7}$ & $5.60 \times 10^{-8}$ & $1.52 \times 10^{-7}$ \\
\hline LSZO SPS & $1.87 \times 10^{-4}$ & - & $3.42 \times 10^{-5}$ & - \\
\hline
\end{tabular}

